\title{
Biological Cousin
}

National Cancer Institute

\section{Source}

National Cancer Institute. Biological Cousin. NCI Thesaurus. Code C96571.

A relative who is the offspring of a sibling of either of the biological parents, and who share a common ancestor. 